\title{
INTERAÇÃO ENTRE CRIANÇA-CRIANÇA: UMA ANÁLISE NA PERSPECTIVA WALLONIANA
}

Viviane Aparecida Ferreira Favareto Cacheffo ${ }^{1}$, Gilza Maria Zauhy Garms ${ }^{2}$

${ }^{1}$ Mestre em Educação pela FCT/Unesp; Doutoranda em Educação pela FCT/UNESP. ${ }^{2}$ Docente do Departamento de Educação e do Programa de Pós-graduação em Educação da FCT/UNESP. E-mail: vivianecacheffo@gmail.com. CAPES

\section{RESUMO}

Esse artigo tem por objetivo apresentar as manifestações emocionais que permeiam as interações entre criança e criança, identificando as estratégias que as professoras utilizam para lidar com as expressões de afetividade. A pesquisa qualitativa caracteriza-se como estudo de caso do tipo etnográfico. Nos episódios de interação evidenciados notou-se que as crianças até três anos recorrem ao adulto de referência na creche em praticamente todas as situações vivenciadas, como norte de apoio e segurança. Portanto, tendo por pressuposto que a afetividade - emoção, sentimento e paixão - se manifestam pela ativação provocada pelo outro, adulto ou criança, podemos afirmar que as interações são promotoras dos estados afetivos.

Palavras-chave: Interação criança-criança. Afetividade. Creche. Professor. Teoria Walloniana.

\section{INTRODUÇÃO}

É com o auxílio das interações que a criança evolui em todos os conjuntos funcionais afetivo, motor, cognitivo e da pessoa. As relações com os adultos e demais pessoas que compõem o círculo de convivência infantil permitem a ampliação do repertório de situações e sensações vivenciadas pelas crianças. Portanto, para que ocorra o desenvolvimento psicológico qualitativo da dimensão afetiva, a interação é fundamental. Buscando apresentar processos interativos entre criança-criança, selecionamos três episódios.

\section{Interações entre crianças: dados coletados e análises}

O primeiro episódio demonstra a interação entre os bebês, sendo um deles com seis meses de idade e o outro com onze meses. Em relação aos estágios de desenvolvimento propostos pela teoria walloniana, ambos se situam no período emocional, isto é, os gestos expressivos são o meio de expressão e comunicação dos anseios e vontades do bebê.

L. e G. estavam brincando no colchonete com miniaturas de animais. As duas crianças movimentam os bichinhos e emitem sons. G. pega o bichinho e o coloca perto do olho de L. Quando o outro bebê vai pegá-lo, G. puxa o brinquedo e tenta puxar o cabelo do colega. Nesse momento, a professora Lucilene pega a mão da criança G. e acaricia os cabelos e a face de L., dizendo:

- Carinho, G., você pode fazer carinho. (Observação no agrupamento dos bebês). 
Os bebês usam os recursos dos sentidos - tato, visão, olfato, paladar e audição - e as sensações por eles provocadas como instrumentos de comunicação. Os bebês L. e G. interagem com a ajuda dos movimentos possibilitados pelo corpo e estabelecem, segundo Ajuriaguerra (1983), o diálogo tônico, baseado nos gestos intencionais, portanto, expressivos.

Suas manifestações afetivas se limitaram, primeiro do choro da fome ou da cólica à relaxação da digestão ou do sono. Sua diferenciação primeiro é muito lenta, mas, aos seis meses, o aparelho de que a criança dispõe para traduzir as suas emoções é bastante variado para constituir uma vasta superfície de osmose com o meio humano. É uma etapa importantíssima de seu psiquismo. Seus gestos adquirem uma certa eficiência por intermédio de outrem; os de outrem tornam-se cautelosos. Tal reciprocidade a princípio é um amálgama completo, uma participação total, em que mais tarde terá de delimitar sua pessoa, profundamente fecundada por esta primeira absorção em outrem. (WALLON, 1995, p.219).

Para manter a posse do brinquedo, G. tenta afastar o outro bebê, provavelmente repetindo movimentos já realizados anteriormente e que foram significados pela criança, como forma de garanti-lo. A postura da professora incentiva outra maneira para a resolução da manifestação de G., mostrando mais uma função para as mãos que podem causar desconforto, ou seja, o ato de fazer carinho. Contudo, é necessário pensarmos que, aliado ao significado de cariciar o outro bebê, G. só poderá compreender a desaprovação do gesto em relação a L., se as expressões faciais e o tom de voz da professora indicarem o descontentamento.

Vivenciamos, nesse agrupamento, alguns momentos em que as crianças estavam próximas e, por diversos motivos, dirigiam-se contra as outras, em direção aos cabelos e ao rosto e, quando percebiam o olhar da professora, mudavam o gesto, sinalizando que estavam fazendo carinho e até sorriam, buscando atingir a aprovação das professoras. Essas atitudes se assemelham às do estágio personalista, precisamente a sedução, fase em que a criança procura a atenção do adulto por ações que os agradam.

No segundo episódio:

As crianças estão brincando no pátio. Algumas estão no interior do chalezinho de madeira, outras brincam na lousa que se encontra na parte externa, enquanto B., J. e Gu brincam com os utensílios domésticos em uma mesinha.

Gu pega a jarrinha e diz:

-Vou fazer um suco...

E J. diz:

- Suco de morango?

- É de morango com leite.

Gu distribui os copinhos para as outras crianças e serve o suco. 
- B. "toma o suco" e fala:

- Quero mais, está gostoso. (Observação no agrupamento das crianças pequenas).

O faz-de-conta, acionado pela brincadeira de representação, foi a estratégia usada pelas crianças para simular a produção do suco, o gosto e as características. "Brincar dá a criança oportunidade para imitar o conhecido e para construir o novo, conforme ela reconstrói o cenário necessário para que sua fantasia se aproxime ou se distancia da realidade vivida, assumindo personagens e transformando objetos pelo uso que deles faz" (BRASIL, 2009, p. 7).

Os sujeitos da observação encontram-se no estágio sensório-motor e projetivo, período no qual a linguagem gestual é substituída gradualmente pela verbal, e as ações anteriormente realizadas de forma concreta passam a ser executadas de forma mental, a partir da conquista e consciência do eu corporal. Assim, as interações podem acontecer de maneira satisfatória, dependendo da organização dos ambientes e estímulos.

O terceiro episódio apresenta uma interação ocorrida pelas crianças no momento da recepção. Como a professora prepara a sala, disponibilizando materiais para a confecção de desenhos, tornou-se imperioso tecer considerações sobre essa estratégia de representação que permite a exteriorização e a expressão gráfica dos estados emocionais.

Em estudo realizado por Silva e Sommerhalder (1999), constatamos que a prática do desenho é vista como uma ação para o preenchimento dos tempos vagos que não têm o reconhecimento, como das demais áreas do conhecimento que constituem o currículo da Educação Infantil.

Ainda segundo as autoras,

[...] o trabalho desenvolvido muitas vezes possui um enfoque distorcido, pois perde a função de expressão pessoal, manifestação do lado emocional, algo que ajuda a criança a desenvolver seu interesse em conhecer, descobrir, inventar para tornar-se uma atividade que acalma as crianças, treina a coordenação motora, serve para "matar o tempo". (SILVA; SOMMERHALDER, 1999, p. 241).

Silva e Sommerhalder (1999) destacam a importância de a prática do desenho ser repensada pelos profissionais que atuam na Educação Infantil, sendo necessária uma formação na área de Artes, para que planejem momentos em que o ato de desenhar se torne um recurso que auxilia e promove o desenvolvimento integral infantil. 
No caso da situação analisada, a professora usou o desenho como uma das atividades que as crianças poderiam escolher, além das demais que sempre estão à disposição das crianças (brinquedos de encaixe, livros, brinquedos) e interagiu com elas, para saber os significados do desenho realizado.

A professora Zenaide organizou a sala de recepção das crianças com folhas para desenho, giz de cera e canetinhas.

J. chega à sala e dirige-se para mesa, pega uma folha e começa a desenhar.

- O que está desenhado?

- Mamãe, papai e minha irmã.

- E você?

- Ainda vou desenhar.

- O que vocês estão fazendo?

- Vamos passear.

Outra criança, Gi, mostra seu desenho à professora e também é questionada.

J e Gi começam a mostrar uma para a outra os personagens do desenho que fizeram.

Embora, inicialmente, o episódio relate a interação entre professora-criança, o seu desfecho evidencia que a mediação do adulto culminou com o envolvimento das crianças. Diante dessa constatação, consideramos importante registrar a dificuldade de captar as interações somente entre criança-criança, pois, na maioria das situações, é inevitável a mediação da professora. Pensando em estratégias para ampliar o registro de situações de interação para pesquisas futuras, acreditamos ser fundamental a utilização de outros recursos metodológicos, além da observação, como, por exemplo, a gravação em vídeo.

\section{ALGUMAS CONSIDERAÇÕES:}

Nos episódios de interação evidenciados notou-se que as crianças até três anos recorrem ao adulto de referência na creche em praticamente todas as situações vivenciadas, como norte de apoio e segurança.

Desta forma, o professor como mediador qualificado e promotor de interações, precisa ter subsídios teóricos para compreender que o desenvolvimento afetivo da criança, que na perspectiva walloniana é composto por uma gama de manifestações, que possibilita à criança a satisfação de suas necessidades. As expressões emocionais facilitam o desvelar de tonalidades agradáveis e desagradáveis. A inteligência, por via da representação, permite formas mais elaboradas para a afetividade se manifestar. 
Para Barbosa (2009, p.3), o professor precisa ser o mediador das relações estabelecidas entre as crianças e os adultos. É sua função promover interações sociais e afetivas que auxiliem na constituição da consciência infantil. "Esse é um importante papel da Educação Infantil, principalmente no que se refere as crianças bem pequenas, pois é nessa faixa etária que as interações entre as pessoas têm expressiva relevância para a construção das identidades pessoal e coletiva da criança".

Conforme o Parecer CEB 20/2009 (BRASIL, 2009, p. 7),

[...] as professoras e os professores têm, na experiência conjunta com as crianças, excelente oportunidade de se desenvolverem como pessoa e como profissional. Atividades realizadas pela professora ou professor de brincar com a criança, contar-lhe histórias, ou conversar com ela sobre uma infinidade de temas, tanto promovem o desenvolvimento da capacidade infantil de conhecer o mundo e a si mesmo, de sua autoconfiança e a formação de motivos e interesses pessoais, quanto ampliam a possibilidades da professora ou professor de compreender e responder às iniciativas infantis.

Portanto, compreendemos que o professor é o mediador qualificado para auxiliar as crianças nas situações de interação e o ponto de referência e segurança no contexto da creche; “[...] como elemento diferenciado, é o responsável pela unidade do grupo, podendo receber as manifestações das crises infantis com o distanciamento necessário para não as comprimir nem se submeter a elas" (GALVÃO, 1994, p.38).

\section{REFERÊNCIAS}

AJURIAGUERRA, J. Manual de psiquiatria infantil. Rio de Janeiro: Masson do Brasil, 1983.

BARBOSA, M. C. Especificidades da ação pedagógica com os bebês. In: Programa Currículo em Movimento. Disponível em:

http://portal.mec.gov.br/index.php?ltemid=1096\&id=15860\&option=com content\&view=article. Acesso em: 05 dez. 2010.

BRASIL. Ministério da Educação. Conselho Nacional de Educação. Câmara de Educação Básica. Parecer CNE/CEB n20, de 11 de novembro de 2009. Revisão das Diretrizes Curricular Nacional para Educação Infantil.

GALVÃO, I. Henri Wallon: uma concepção dialética do desenvolvimento infantil. Petrópolis, RJ: Vozes, 1994.

SILVA, Silva Maria Cintra da; SOMMERHALDER, Cinara. A percepção do professor de educação infantil sobre o desenho da criança. Educação e Filosofia. Uberlândia, v. 13, n. 26, p.237-258, jul.dez. 1999. Disponível em: 
http://www.seer.ufu.br/index.php/EducacaoFilosofia/article/view/777/700 Acesso em: 10 jun.2010.

WALLON, H. A evolução psicológica da criança. Lisboa: Edições 70, 1995 